such as the European multicentre study reported in this issue (p 411), confirms that the probability that HIV infection will be transmitted is influenced by factors such as the presence of other sexually transmitted diseases. ${ }^{10}$

Anderson and May recently estimated that the reproductive rate for the general population may be just above or just below unity. ${ }^{12}$ If it is below the infection will continue to spill over into the heterosexual community but will not propagate widely. If it is just above (say $1 \cdot 1$ ) the doubling time of the heterosexual epidemic during the early stages might be about 8-14 years. As the proportion of people infected with $\mathrm{HIV}$ is currently a fraction of $1 \%$ it will be extremely difficult to confirm such a slowly developing, but potentially catastrophic, epidemic. The need for careful epidemiological research is clear. We can look to the United States (where the epidemic is further advanced) for clues, but even there it is too early to discern what is happening. The prevalence of HIV infection in patients from a sexually transmitted disease clinic in Baltimore ${ }^{13}$ was higher than that in London reported in this issue, but still no evidence exists of an explosive heterosexual epidemic in the United States. ${ }^{1+15}$ If the rates of sexual partnership are different, of course, the reproductive rate could be just below unity in one developed country and just above in another.

Governments are therefore right to warn heterosexual populations that they face a serious threat. The task for health educators is monumental because for most people at present the risk of infection in a single sexual encounter is exceedingly small. The risk in one heterosexual encounter (without a condom) with a person infected with HIV has been estimated at about one in 500 , while the risk for one encounter with an American who is not in any high risk group might be of the order of one in 5 million. ${ }^{16}$ Yet if we fail to maintain public commitment to control measures a major heterosexual epidemic in the future is still a real possibility.

Professor of Preventive and Social Medicine,

D C G SKEGG

University of Otago,

Dunedin,

New Zealand

1 Anonymous. 'Too much panic over AIDS? Nature 1987;326:113-4.

2 Piot P, Plummer FA, Mhalu FS, Lamboray J-L, Chin J, Mann JM. AIDS: an international perspective. Science 1988;239:573-9.

Gunson HH, Rawlinson VI. AIDS update. Br Med $\mathcal{f}$ 1988;297:244

4 Anderson RM, Medley GF. Epidemiology of HIV infection and AIDS: incubation and infectious periods, survival and vertical transmission. AIDS 1988;2(suppl 1):57-63.

5 Hull HF, Bettinger CJ, Gallaher MM, Keller NM, Wilson J, Mertz GJ. Comparison of HIV antibody prevalence in patients consenting to and declining HIV-antibody testing in an STD antibody prevalence in patien
clinic. JAMA 1988:260:935-8.

6 Carne CA, Weller IVD, Sonnex C, Johnson AM, Petherick AM, Adler MW. Heterosexual transmission of HIV infection. Lancet 1987; ii:41.

Allen JR. Heterosexual transmission of human immunodeficiency virus (HIV) in the United States. Bull NY Acad Med 1988;64:464-79.

8 Castro $\mathrm{KG}$, Lifson $\mathrm{AR}$, White $\mathrm{CR}$, el al. Investigations of AIDS patients with no previously identified risk factors. FAMA 1988;259:1338-42.

9 May RM, Anderson RM. Transmission dynamics of HIV infection. Nature 1987;326:137-42.

10 Johnson AM, Laga M. Heterosexual transmission of HIV. AIDS 1988;2(suppl 1):49-56.

11 Quinn TC, Piot P, McCormick JB, et al. Serologic and immunologic studies in patients with AIDS in North America and Africa. FAMA 1987;257:2617-21.

12 Anderson RM, May RM. Epidemiological parameters of HIV transmission. Nature 1988:333: 514-9.

13 Quinn TC, Glasser D, Cannon RO, et al. Human immunodeficiency virus infection among patients attending clinics for sexually transmitted diseases. N Engl f Med 1988;318:197-203.

14 Centers for Disease Control. Human immunodeficiency virus infection in the United States: a review of current knowledge. MMWR 1987;36(suppl S-6): 1-48.

15 Centers for Disease Control. Quarterly report to the Domestic Policy Council on the prevalence and rate of spread of HIV and AIDS - United States. MMWR 1988;37:551-9.
rate

16 Hearst N, Hulley SB. Preventing the heterosexual spread of AIDS. Are we giving our patients the best advice? FAMA 1988;259:2428-32.

\title{
Music and disability
}

\section{Music will benefit disabled people}

Rhythm and harmony, says Plato, sink into the depths of the soul. ${ }^{1}$ Music is said to be anciently related to magic and the supernatural, ${ }^{2}$ and its power is still apparent. People with physical disabilities need access to music as much as anyone else-perhaps more, because they often have empty hours to fill. Some may also benefit specifically, and the many ways in which music might help disabled people were explored recently in a seminar at the Royal Hospital and Home, Putney. One important source of information on the subject is the Disabled Living Foundation's music advisory service (380-4 Harrow Road, London W9 2HU). It has its own extensive resources and also refers inquirers to particular experts or to local education authority music advisers.

Disabled people still face problems of physical access in attending concerts, and this is improving only slowly, though the provision of special projects for disabled people is increasing. ${ }^{+5}$ Technology and simple ingenuity have made things better, and no one should lack the means of using hi fi or other equipment or of making music in some way. The most severely disabled may use the new Possum environmental and communication control system (PSU6) to control hi fi equipment extremely easily, and this system also allows access to computer music. Many adaptations and gadgets are available for equipment and instruments for those with less severe disabilities. People with hemiplegia, for instance, may play a range of instruments and also draw on a repertoire of piano music for one hand. Exciting developments with the computer as a musical instrument and medium for composition for disabled people are in progress in the University of York's electronics department.

Many disabled people, however, benefit from having access to music in hospital, hospice, or residential home, or even from having it brought to their own home. The Council for Music in Hospitals arranges concerts by professional musicians chosen for their ability to relate sensitively to people ${ }^{6}$; the concerts may evoke enthusiastic and sometimes profound responses, even from withdrawn people. At St Joseph's Hospice, Hackney, musicians play at the bedside; and in the Chelmsford hospice service a local violinist visits patients at home - and one woman even had guitar lessons in her last days. General practices and hospital leagues of friends might find volunteer musicians to help in these ways. The use of personal stereos might be encouraged more, and staff could - and sometimes do - build music into daily life. In old people's homes, for instance, old time songs are both pleasurable and good reminiscence therapy. Simple and unusual ideas abound for music making in such settings, and the Manchester arts for health project is an important model in promoting all the arts in hospitals and elsewhere. ${ }^{7}$ Beyond immediate delight, music may provide a way of getting in touch with feelings and a bridge to communication, which may be especially important in terminal care. ${ }^{89}$

Music as specific therapy is the responsibility of qualified music therapists. Traditionally music therapy has been used mainly for children with mental or multiple handicaps and for adults with mental illness; yet music has specific physical 
effects, ${ }^{10}$ influencing autonomic function, ${ }^{2}$ and may bring psychological benefits to people with disabilities. For the elderly music therapy has clear benefits, ${ }^{11}$ and there is anecdotal evidence of benefit among people with head injuries. At Putney a music therapist works with patients in the head injury unit, and a formal study is being developed. Patients with Huntington's chorea have derived short term benefit as well as enjoyment from music therapy. ${ }^{1213}$ Several studies have shown promising results in Parkinson's disease..$^{1+16}$ Here music helps patients to walk and to overcome "freezing" episodes, and in conjunction with speech therapy it may improve the intelligibility of speech; music also helps relaxation and lifts depression.

There is a need for more studies of the effects of music therapy (including its combination with other therapies). But the more general and subjective benefits to the whole person, which do not depend on musical talent, are at least as important: enriching life; increasing well-being, self esteem, and motivation; providing comfort or emotional experience and a bridge to other people; and developing potential. ${ }^{8-1+16}$ Creating an awareness of the potential of the creative arts therapies during training for various professions has been recommended, ${ }^{4}$ and a start has been made, especially in nurse training.

Staff editor, $B M \mathcal{F}$

DAPHNE GLOAG

1 Plato. Republic. Book III, 401d.

2 Alvin J. Music therapy. London: Hutchinson, 1975.

3 Barton M, Stewart A, eds. British music education yearbook. London: Rhinegold (published yearly).

4 Carnegie UK Trust. Arts and disabled people. London: Bedford Square Press, 1985. (Attenborough report.)

Carnegie Council Review. After Attenborough: arts and disabled people. London: Bedford Square Press, 1988.

6 Graham J. Music has a key role in health care. GP Weekly Briefing 1987 Sept 11:49. (See also Council for Music in Hospital's Progress Report 1987; obtainable from the council at 340 Lower Road, Little Bookham, Surrev KT23 4EF.

Sheeran I. Arts for health. Br Med F 1988;297:1667-9.

8 Munro S. Mount B. Music therapy in palliative care. Can Med Assoc 7 1978;119:1029-34.

9 Frampton DR. Restoring creativity to the dying patient. Br Med f 1986;293:1593-5.

9 Frampton DR. Restoring creativity to the dying patient. Br Med f 1986;293:1593-5. nallow M. Can music help people with Parkinson's disease? In: Rose FC,
neurology. Vol 6: Parkinson's disease. London: John Libby, 1987:109-12.

1 Bright R. Practical planning in music therapy for the aged. Lynbrook, New York: Musicgraphics, 1981. (Available from Musigraphics, 230 Purley Road, Croydon CR0 4XG.)

12 Hoskyns S. Striking the right chord. Nursing Mirror 1982 Jun $2: 14-7$. (Report also available from the Association to Combat Huntington's Chorea, 108 Battersea High Street, London SW11 3HP.)

13 Perry MR. Music therapy in the care of Huntington's disease patients. Australian Music Therapy Association Bulletin 1983;6(Dec):3-10.

14 Cosgriff V. Music and parkinsonism. British fournal of Music Therapy 1986;17:13-8.

15 Crozier E, Hamill R. The benefits of combining speech and music therapy. Speech Therapy in Practice 1988 Nov:9-10.

16 Selman J. Music therapy with Parkinson's disease. Fournal of British Music Therapy 1988;2:5-9.

\title{
Adverse effects of inhaled corticosteroids
}

\author{
Not serious if care is taken
}

An inhaled corticosteroid is now the main agent used for prophylaxis in adult asthma and increasingly so in children. Administration of large doses of inhaled corticosteroids, aided by more concentrated aerosol preparations and improved delivery devices, has allowed further reductions in the use of oral corticosteroids. So it has to be asked what is the balance of advantages and disadvantages of these agents.

Inhaled corticosteroids are usually well tolerated. Thrush occurs in $5-13 \%$ of adults ${ }^{1-3}$ and $1 \%$ of children ${ }^{+}$; the frequency relates to the dose ${ }^{2}$ and its frequency ${ }^{3}$ and may be reduced with spacer devices. ${ }^{5}$ Dysphonia due to a reversible vocal cord deformity, resulting from laryngeal myopathy, is less common. ${ }^{6}$ Treatment rarely has to be stopped because of thrush, and dysphonia may not recur if lower doses are tried. Posterior subcapsular cataracts have now been reported in one child $^{7}$ and three adults ${ }^{8}$ taking inhaled beclomethasone dipropionate for two to 12 years with occasional short courses of oral corticosteroids and were attributed to the inhaled corticosteroid.

In adults suppression of the adrenal glands from systemic absorption may occur with a dose of beclomethasone dipropionate above $1500 \mu \mathrm{g}$ daily. ${ }^{910}$ In children dose dependent suppression of the adrenal glands has been reported with doses as low as $400 \mu \mathrm{g}$ daily, "which has led to concern about their effect on growth. Asthma may itself stunt growth, although in a cross sectional study reduced stature was found to be as common in children with rhinitis alone. ${ }^{12}$ No effect on growth was seen over three to five years in 19 asthmatic children taking doses of around $400 \mu \mathrm{g}$ of beclomethasone dipropionate daily. ${ }^{13} \mathrm{~A}$ recent cross sectional study compared the growth of 81 asthmatic children having doses of 200-800 $\mu \mathrm{g}$ of beclomethasone dipropionate daily (mean $15 \mu \mathrm{g} / \mathrm{kg}$ body weight) with that of 249 asthmatic children receiving other treatment, finding that height was half a standard deviation less in those treated with beclomethasone dipropionate. ${ }^{14}$ Although this suggests that beclometha- sone dipropionate may retard growth, other explanations are possible. Those having beclomethasone dipropionate were older and may have had more severe disease; alternatively, asthma itself may well delay puberty, thus causing the small growth impairment seen in the older, beclomethasone treated children. ${ }^{15}$ Delay in puberty occurred in 30 patients in a longitudinal study of 66 asthmatic children followed for a mean of $13 \cdot 1$ years but final heights were judged to be normal. ${ }^{16}$ In 26 children receiving up to $600 \mu \mathrm{g}$ beclomethasone dipropionate daily for a mean of 5.8 years growth in height was apparently inhibited by delayed puberty in 11 , but they later regained their predicted height. ${ }^{16}$ The possibility remains then that inhaled corticosteroids may stunt growth, but with standard paediatric doses it is unlikely to become a clinical problem.

Metabolic studies in healthy adults taking $500 \mu \mathrm{g}$ of beclomethasone dipropionate twice daily, a dose not usually associated with adrenal suppression, have shown decreased insulin sensitivity and small but significant rises in both total and high density lipoprotein cholesterol concentrations. ${ }^{17}$ The importance of these changes is uncertain, although even small increases in plasma cholesterol concentrations within the accepted normal range are thought to increase the risk of cardiovascular disease. ${ }^{18}$ There is also some evidence to suggest that inhaled corticosteroids cause osteoporosis: doses of $400-800 \mu \mathrm{g}$ daily may reduce the total body calcium to values similar to those found in postmenopausal patients with crush fractures. ${ }^{19}$

Inhaled corticosteroids are an integral part of the management of asthma. Nevertheless, dosage requires titration, with increasing doses being prescribed for continuing symptoms, low mean peak expiratory flow values, or unacceptable diurnal variations of peak flow. Towards the end of the therapeutic dosage range few adverse effects in the short or long term are expected but the doctor should be aware of the metabolic effects of higher doses that are insufficient to cause 